\title{
Cytogenetic Studies and Evolutive Considerations on Fishes of the Family Cichlidae (Perciformes) from Parana River (Argentina)
}

\author{
Héctor Alberto Roncati, María Cristina Pastori \\ and Alberto Sergio Fenocchio

\begin{abstract}
Universidad Nacional de Misiones, Facultad de Ciencias Exactas, Químicas y Naturales, Departamento de Genética, Cátedra de Citogenética General, Félix de Azara 15523300 Posadas, Misiones, Argentina
\end{abstract}

Received October 30, 2006; accepted November 18, 2006

\begin{abstract}
Summary Among the Perciformes, Cichlidae represent the more specious group, geographically distributed in Africa, Asia and America. In the present work, 7 species of 5 genera of cichlids from the Paraná River (Misiones, Argentina) were cytogenetically characterized and discussed some aspects of the chromosome evolution. The following chromosome numbers and formulaes: were found for each analyzed species: Crenicichla niederleinii $2 n=48$ (6 M-SM; 42 ST-A), Crenicichla lepidota $2 n=48$ (6 M-SM; 42 ST-A), Gymnogeophagus sp. n. $2 n=48$ (2 M-SM; 46 ST-A), Gymnogeophagus balzanii $2 n=48$ (2 M-SM; 46 ST-A), Apistogramma trifasciata $2 n=46$ (16 M-SM; 30 ST-A), Cichlasoma dimerus $2 n=48$ ( 8 M-SM; 40 ST-A) and Bujurquina vittata $2 n=44$ (22 M-SM; 8 ST-A; 14 microchromosomes). The C-positive heterochromatin was observed preferentially in pericentromeric regions of some chromosomes and NORs at the secondary constriction on the first chromosome pair. In $B$. vittata the microchromosomes are not heterochromatic and the 5th pair shows short arms entirely stained and, in coincidence, the AgNORs appears located at the same region. The results obtained evidence a wide chromosomal variation, either in number and structure that could be integrated with morphological and molecular data in phylogenetic studies.
\end{abstract}

Key words Fishes, Cichlidae, Cytogenetics.

Among the Perciformes, the Cichlidae family shows the highest species number in freshwater and are distributed in Africa, Asia and America, along the Neotropical Region. At now have been described about 450 species (Kullander 1998) and new species are continuously being described (Kullander 2004, López-Fernández and Taphorn 2004, Ready and Kullander 2004, Schelly and Stiassny 2004, Staeck and Schindler 2005).

With the background of discoveries on Cichlidae biodiversity in the great lakes of Eastern Africa, new hypothesis and theories are built to explain the adaptive radiations of the group (Nagl et al. 1998, Albertson et al. 1999, Kocher 2004, Salzburger et al. 2005). The first cytotaxonomic studies (Thompson 1979) showed that cichlides maintain the karyotype macrostructure with $2 n=48$ chromosomes, varying slightly by means of pericentric inversions and deletions. However, in some further reports including other techniques (C-bands, AgNORs) were studied species from Brazil, showing variation in chromosome number and morphology (Feldberg and Bertollo 1985a, b, Martins-Santos et al. 1995, 2005, Salgado et al. 1994, Brum et al. 1998, Loureiro et al. 2000). In the present paper were cytogenetically characterized species belonging to 5 genera of cichlids from the Paraná River (Misiones, Argentina), discussing some aspects about the chromosome evolution of the group.

* Corresponding author, e-mail: hroncati@gwail.com 


\section{Materials and methods}

Were cytogenetically analyzed 120 individuals of the Cichlidae family, belonging to the following subfamilies: Cichlinae: Crenicichla niederleinii, Crenicichla lepidota; Geophaginae: Gymnogeophagus sp. n., Gymnogeophagus balzanii, Apistogramma trifasciata and Cichlastomatinae: Cichlasoma dimerus, Bujurquina vittata (Kullander 1998). Samples were collected at the Paraná River (Posadas, Misiones, Argentina).

Mitotic preparations were obtained from kidney cells according the techniques of Bertollo et al. (1978) and Fenocchio et al. (1991). C-banding and nucleolus organizer regions were evidenced as described by Sumner (1972) and Howell and Black (1980), respectively. Chromosomes were arranged in karyotypes and classified as metacentric (M), submetacentric (SM), subtelocentric (ST) and acrocentric (A) (Guerra 1986).

\section{Results and discussion}

Were found for each analyzed species the following diploid numbers and chromosome formulaes: Crenicichla niederleinii $2 n=48$ (6 M-SM; 42 ST-A) (Fig. 1a), Crenicichla lepidota $2 n=48$ (6 M-SM; 42 ST-A) (Fig. 2a), Gymnogeophagus sp. n. 2n=48 (2 M-SM; 46 ST-A) (Fig. 3a), Gymnogeophagus balzanii $2 n=48$ (2 M-SM; 46 ST-A) (Fig. 4a), Apistogramma trifasciata $2 n=46$ (16 MSM; 30 ST-A) (Fig. 5a), Cichlasoma dimerus $2 n=48$ (8 M-SM; 40 ST-A) (Fig. 6a) and Bujurquina vittata $2 n=44$ (22 M-SM; 8 ST-A; microchromosomes) (Fig. 7a).

The C-positive heterochromatin was located in pericentromeric regions of some chromosomes in Crenicichla niederleinii, Gymnogeophagus sp. n. and Gymnogeophagus balzanii (Figs. 1b, 3b and 4b). In Crenicichla lepidota C-banding evidenced great blocks and some chromosomes totally heterochromatic (Fig. 2b). In some of these species the NORs were located on the secondary constriction in the first chromosome pair (Figs. 1c and 4c).

In Cichlasoma dimerus the greather part heterochromatin are in the pericentromeric region, being observed conspicuous bands on some small chromosomes (Fig. 6b). Apistogramma trifasciata and Bujurquina vittata also show some pericentromeric weak C-bands, with size and stain variations (Figs. 5c and 7c). In B. vittata the microchromosomes are not heterochromatic and the pair 5th shows their short arms entirely stained (Fig. 7b) and, in coincidence, the AgNORs are appears located on these same regions (Fig. 7c).

Here are confirmed the cytogenetic characteristic of some species and reported for the first time the karyotypes of other, and could be observed, in agreement with the available literature that several of the studied species showed $2 n=48$ indicating the conservatism of the karyotypic macrostructure, characteristic trait of the Order and Family (Thompson 1979). Among the Cichlinae, Crenicichla presents $2 n=48$ with 2 to 8 biarmed chromosomes (Martins et al. 1995, Loureiro et al. 2000) and due to these karyotype characteristics these group could be located with Chaetobranchinae in a basal phylogenetic level in relation to the rest of the Neotropical Cichlidae (Brum et al. 1998, Kullander 1998).

Among the Geophaginae, Apistogramma trifasciata $(2 n=46)$ have shown a reduction in the chromosome number related with an increase in the number of biarmed ones, suggesting that centric fusions could be important in the evolution of the group (Oliveira et al. 1988). Gymnogeophagus $(2 n=48 ; \mathrm{NF}=50-52)$ and Guianacara $(2 n=48 ; \mathrm{NF}=52)$ have nearly basal karyotypes among the Perciformes, however, Apistogramma that is considered a more derivate genus, show diploid numbers ranged from 38 to 46 and 48 with $\mathrm{NF}=60$ and 70 (Brum et al. 1998).

Bujurquina vittata (Cichlasomatinae) have the lower chromosome number among the studied species, almost all biarmed, few acrocentric and 14 microchromosomes, features that clearly evidence the complex rearrangements occurred along the evolution of this specie. In Neotropical cich- 


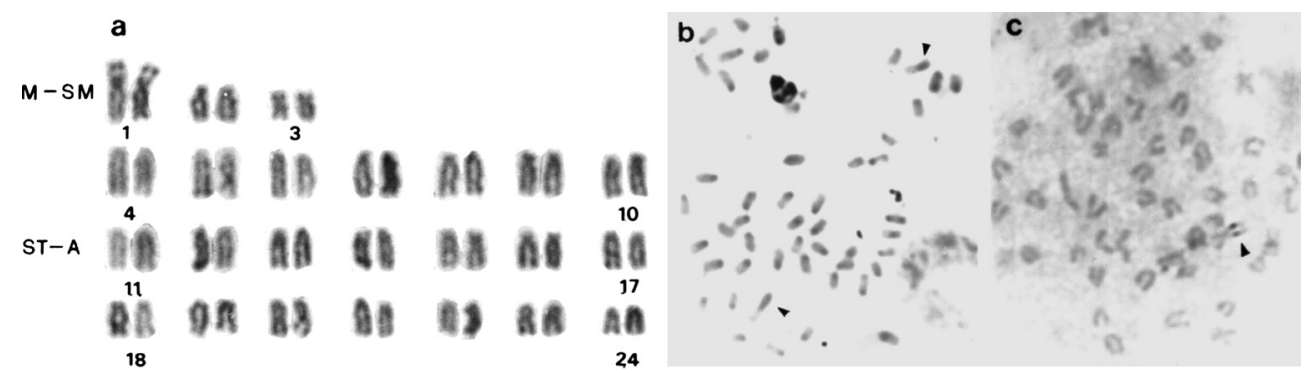

Fig. 1. Crenicichla niederleinii. a. Karyotype $2 n=48$, b. C banding, c. NOR banding the arrows indicate NORs regions.

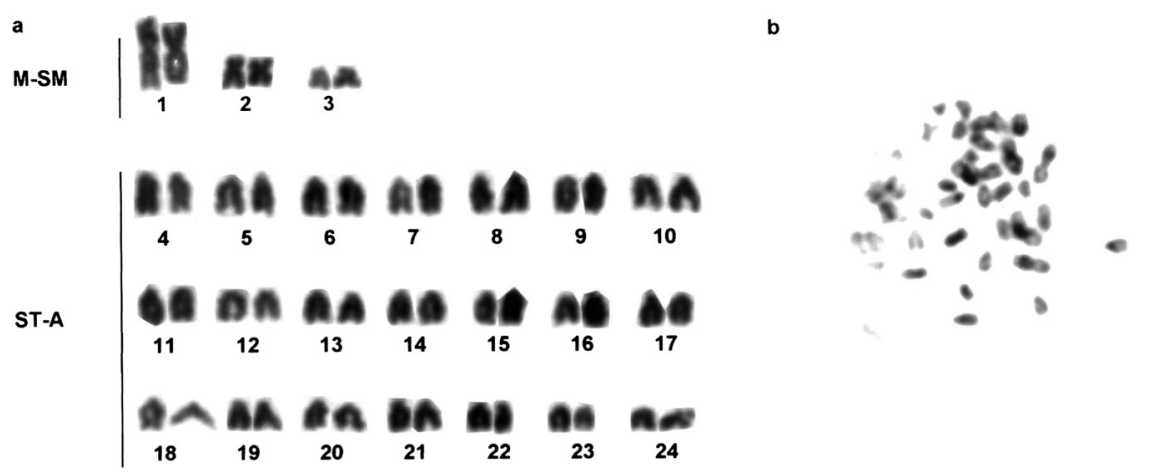

Fig. 2. Crenicichla lepidota. a. Karyotype $2 n=48$, b. C banding.

a

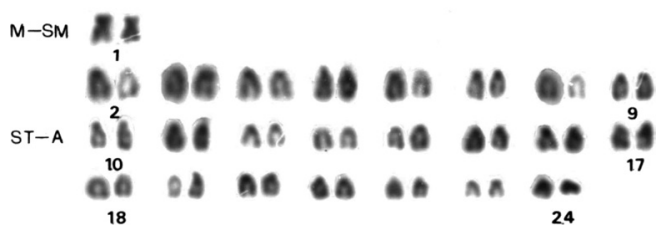

Fig. 3. Gymnogeophagus sp. n. a. Karyotype $2 n=48$.
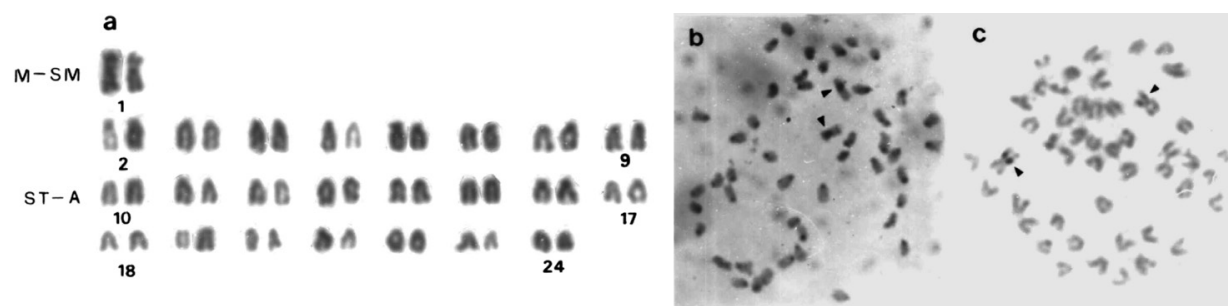

Fig. 4. Gymnogeophagus balzanii. a. Karyotype $2 n=48$, b. C banding, c. NOR banding. 
a

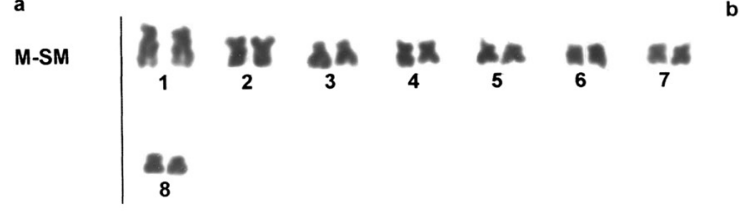

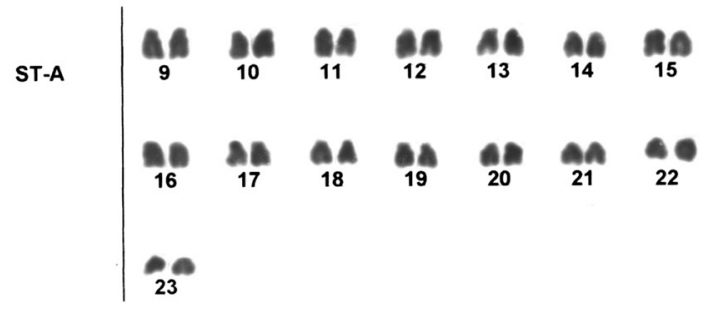

Fig. 5. Apistogramma trifasciata. a. Karyotype $2 n=46$, b. C banding arrows indicate NORs regions.

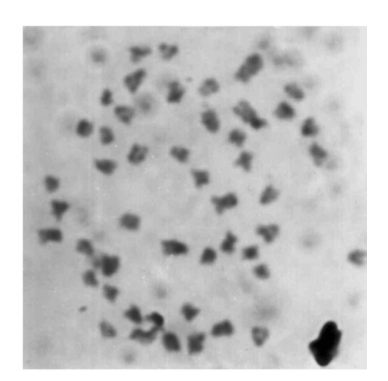

b

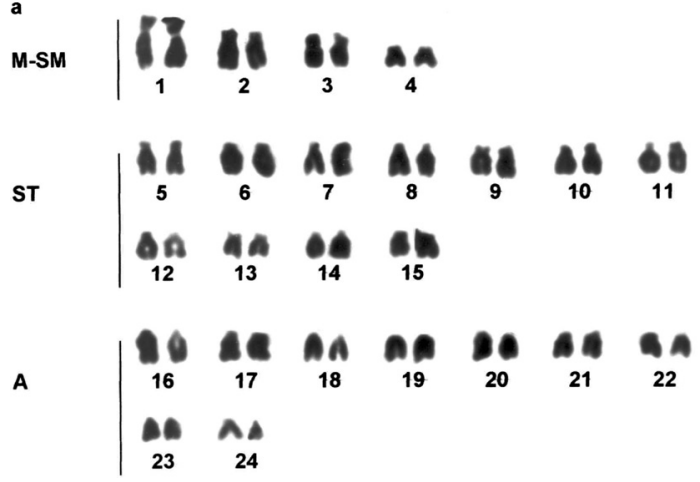

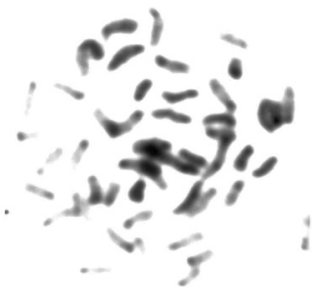

Fig. 6. Cichlasoma dimerus. a. Karyotype $2 n=48$, b. C banding.

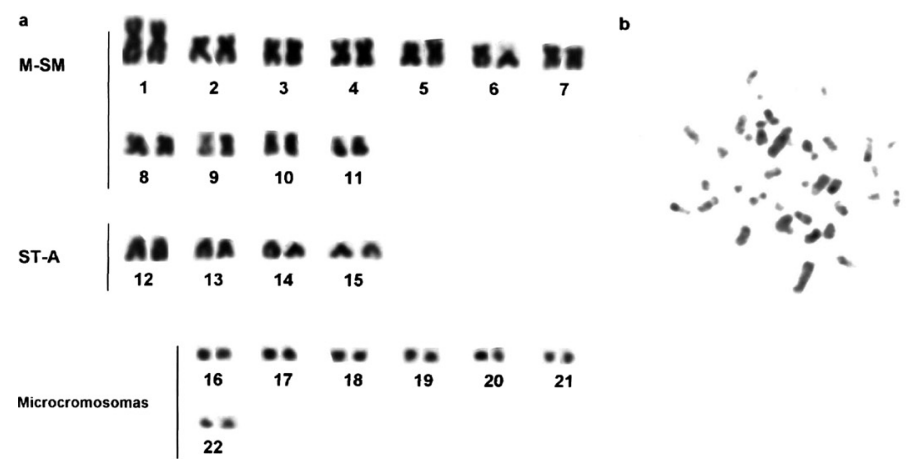

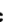

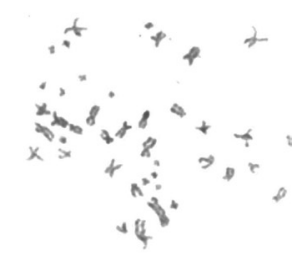

Fig. 7. Bujurquina vittata. a. Karyotype $2 n=44$, b. C banding, c. NOR banding, the arrows indicate NORs regions. 
Table 1. Chromosome numbers and morphology of the studied species (M-SM, ST-A and Microchromosomes)

\begin{tabular}{lccccc}
\hline \hline \multirow{2}{*}{ Species } & Diploid number & \multicolumn{3}{c}{ Chromosome types } \\
\cline { 3 - 6 } & & NF & M-SM & ST-A & Microchromosomes \\
\hline Crenicichla lepidota & 48 & 54 & 6 & 42 \\
Crenicichla niederieinii & 48 & 54 & 6 & 42 \\
Gymnogeophagus balzanii & 48 & 50 & 2 & 46 \\
Gymnogeophagus sp. $\mathrm{n}$. & 48 & 50 & 2 & 46 \\
Cichlasoma dimerus & 48 & 56 & 8 & 40 \\
Apistogramma trifasciata & 46 & 62 & 16 & 30 & 14 \\
Bujurquina vittata & 44 & 66 & 22 & 8 & 14 \\
\hline
\end{tabular}

lids have been reported only another case of microchromosomes in Symphysodon discus (Salgado et al. 1994). On the other hand, in Laetacara dorsigera, from the Paraná River (Brazil), belonging to the same subfamily, were found 4 cytotypes, with variation in number and chromosome morphology (Martins et al. 2005), evidencing a particular evolution pathway. Supporting these observations, the molecular data suggest that this subfamily represent the more derivative lineage of the Neotropical cichlids (Farias et al. 1998). All the karyotype features, chromosome numbers and formulaes are summarized in Table 1.

C-banding revealed pericentromeric heterochromatic blocks in some chromosomes of the species with $2 n=48$, except Crenicichla lepidota and Cichlasoma dimerus, and a not-regular pericentromeric, interstitial and telomeric distribution in Apistogramma trifasciata $(2 n=46)$ and $\mathrm{Bu}$ jurquina vittata $(2 n=44)$. Variation in amount and localization of C-bands reveals that events as duplication and rearrangement of heterochromatin were important in the evolution of these species.

Present data, obtained from species belonging to several subfamilies evidence, contrarily to the general view of the Cichlidae as a highly conservative group, a broad chromosomal variation, either in number and structure, that could be integrated with morphological and molecular ones in phylogenetic studies.

\section{Acknowledgements}

Authors are grateful to R. Reis (PUCRGS) for classification of some species and to Secretaría de Políticas Universitarias (Programa de Incentivo a Docentes Investigadores).

\section{References}

Albertson, R. C., Markert, J. A., Danley, P. D. and Kocher, T. D. 1999. Phylogeny of a rapidly evolving clade: The cichlid fishes of Lake Malawi, East Africa (adaptive radiation sexual selection speciation amplified fragment length polymorphism lineage sorting). Proc. Natl. Acad. Sci. USA 96: 5107-5110.

Bertollo, L. A. C., Moreira-Filho, O. and Galetti Jr., P. M. 1986. Cytogenetics and Taxonomy: Considerations based on chromosome studies of freshwater fish. Journal of Fish Biology 28: 153-159.

—, Takahashi, C. S. and Moreira Filho, O. 1978. Cytotaxonomy considerations on Hoplias lacerdae (Pisces: Erythrynidae). Brazil. J. Genet. 2: 17-37.

Brum, M. J. I. and Galetti Jr., P. M. 1997. Teleostei Ground Plan Karyotype. Journal of Comparative Biology 2: 91-102.

—, Oliveira, C. C., Voigt, N. and Correa, M. M. O. 1998. Karyotypic discrepancy between populations of Geophagus brasiliensis (Perciformes: Cichlidae), including the topotypical population, with possible taxonomic implications. Journal Comp. Biology 3: 176-184.

Farias, I. P., Schneider, H. and Sampaio, I. 1998. Molecular phylogeny of Neotropical Cichlids: The Relationships of Cichlasomines and Heroines. In: Malabarba, L. R., Reis, R. E., Vari, R. P., Lucena, Z. M. S. and Lucena C. A. S. (eds.). Phylogeny and Classification of Neotropical Fishes. EDIPUCRS, Porto Alegre: 499-508. 
Feldberg, E. and Bertollo, L. A. C. 1985a. Karyotypes of 10 species of Neotropical cichlids (Pisces, Perciformes). Caryologia 38: 257-268.

— and Bertollo, L. A. C. 1985b. Nucleolar organizing regions in some species of Neotropical cichlid fish (Pisces, Perciformes). Caryologia 38: 319-324.

Fenocchio, A. S., Venere, P. C., Cesar, A. C. G., Dias, A. L. and Bertollo, L. A. C. 1991. Short term culture from solid tissues of fishes. Caryologia 44: 161-166.

Galetti Jr., P. M., Bertollo, L. A. C. and Moreira-Filho, O. 1994. Trends in chromosome evolution of neotropical characiform fishes. Caryologia 47: 289-297.

Guerra, M. S. 1986. Reviewing the chromosome nomenclature of Levan et al. Brazilian Journal of Genetics 9: 741-743.

Howell, W. N. and Black, D. A. 1980. Controlled silver staining of nucleolus organizer regions with a protective colloidal developer: A one step method. Experientia 36: 1014-1015.

Kocher, T. D. 2004. Adaptive evolution and explosive speciation: the cichlid fish model. Nature Reviews Genetics 5: 288-298.

Kullander, S. O. 1998. A Phylogeny and Classification of the South American Cichlidae (Teleostei: Perciformes). In: Malabarba, L. R., Reis, R. E., Vari, R. P., Lucena, Z. M. S. and Lucena, C. A. S. (eds.). Phylogeny and Classification of Neotropical Fishes. EDIPUCRS, Porto Alegre. pp. 461-498.

Levan, A., Fredga, K. and Sandberg, A. A. 1964. Nomenclature for centromeric position on chromosomes. Hereditas 52: 201-220.

Loureiro, M. A., Giuliano Caetano, L. and Dias, A. L. 1999. Cytogenetic Characterization of Two Species of the Genus Crenicichla. Cytologia 65: 57-63.

Martins, I. C., Portela-Castro, A. L. B., Júlio Jr., H. F. 1995. Chromosome analysis of 5 species of the Cichlidae family (Pisces-Perciformes) from the Parana River. Cytologia 60: 223-231.

Nagl, S., Tichy, H., Mayer, W. E., Takahata, N. and Klein, J. 1998. Persistence of neutral polymorphisms in Lake Victoria cichlid fish (speciationygene trees). Proc. Natl. Acad. Sci. USA 95: 14238-14243.

Oliveira, C., Almeida Toledo, L. F., Foresti, F., Britski, H. and Almeida Toledo Filho, S. 1988. Chromosome Formulae of Neotropical Freshwater Fishes. Brazilian Journal of Genetics 11: 577-624.

Salgado, S. M., Feldberg, E. and Porto, J. I. R. 1994. Estudos citogenéticos na família Cichlidae (Perciformes, Labroidei) da bacia amazônica central. V Simp. Citog. Evol. e Aplicada de peixes: 47.

Salzburger, W., Mack, T., Verheyen, E. and Meyer, A. 2005. Out of Tanganyika: Genesis, explosive speciation, key-innovations and phylogeography of the haplochromine cichlid fishes. BMC Evolutionary Biology. doi: 10.1186/14712148-5-17.

Santos, I. C. M., Santos, I. C. M., Portela-Castro, A. L. B., Julio Jr., H. F. 2005. Chromosomal polymorphism and speciation in Laetacara cf. dorsigera (Pisces, Cichlidae) from the Paraná river, Pr, Brazil. Caryologia 58: 95-101.

Sumner, A. T. 1972. A simple technique for demonstrating centromeric heterochromatin. Expl. Cell Res. 75: $304-306$.

Thompson, K. W. 1979. Cytotaxonomy of 41 species of neotropical cichlidae. Copeia 4: 679-691. 